\title{
Nuclear Techniques for Sustainable Development Goals_-Pakistan’s Perspective
}

\author{
Syed Javaid Khurshid \\ Center for International Strategic Studies, Islamabad, Pakistan
}

\begin{abstract}
The safety, security, and development of a country depend on National Power Elements or factors classified by political scientists on geographical sources. These factors are the capability and capacity of a country to achieve its development aims and objectives such as population and poverty, enough electricity, climate change, availability of water, food production, adequate health facilities, and industrial capacity. The national power elements are interdependent and same of every developed and developing nation, except one or two elements depending on geographical location and population of that country. To strengthen these capability and capacity factors, in 2000 United Nation introduced eight millennium development goals mainly emphasizing on reduction of poverty level up to 50\% by 2015 . Pakistan was able to work on only three of the indicators out of 169 but was unable to achieve any significant progress. On ending of 15 years' time UN again in 2015 introduced more universal and executable 17 sustainable development goals to be accomplished by 2030. Science was recognized as one of the tools to achieve these SDGs. Scientific and industrial development along with technology are an effective source of economic development. Technology as an application of science for the welfare of human being and technological capacity for development of economic infrastructure development is the most powerful national power element. Technology such as Nuclear Technology is one of the best, which is an accurate and advanced and can be adopted to achieve these goals. Article will discuss Nuclear Technology application on SDGs on which Pakistan is already working since 1956 and has an expertise and trained manpower for achieving nine out of these 17 sustainable goals by applying Nuclear Technology.
\end{abstract}

Keywords: development, goals, nuclear, Pakistan, sustainable, techniques

\section{Introduction}

To achieve the national power elements worldwide in September 2000, 189 countries along with 22 international organizations pledged to implement the following Eight Millennium Development Goals (MDGs) to eradicate poverty, hunger, environmental degradation, to improve health, and to reduce illiteracy by 2015 (UN. Org. Report, Oct. 11, 2016).

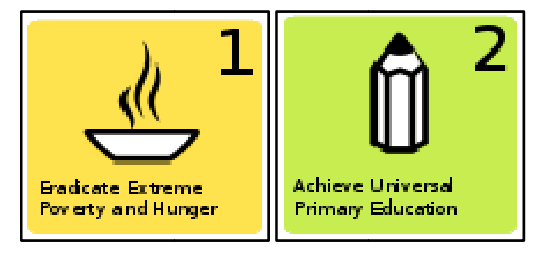

(1) to eradicate extreme poverty and hunger;

(2) to achieve universal primary education;

Syed Javaid Khurshid, Ph.D., distinguished visiting fellow, Center for International Strategic Studies, Islamabad, Pakistan.

Correspondence concerning this article should be addressed to Syed Javaid Khurshid, Centre for International Strategic Studies Suite 506, Evacuee Trust, G-5/1, Agha Khan Road, Islamabad, Pakistan. 


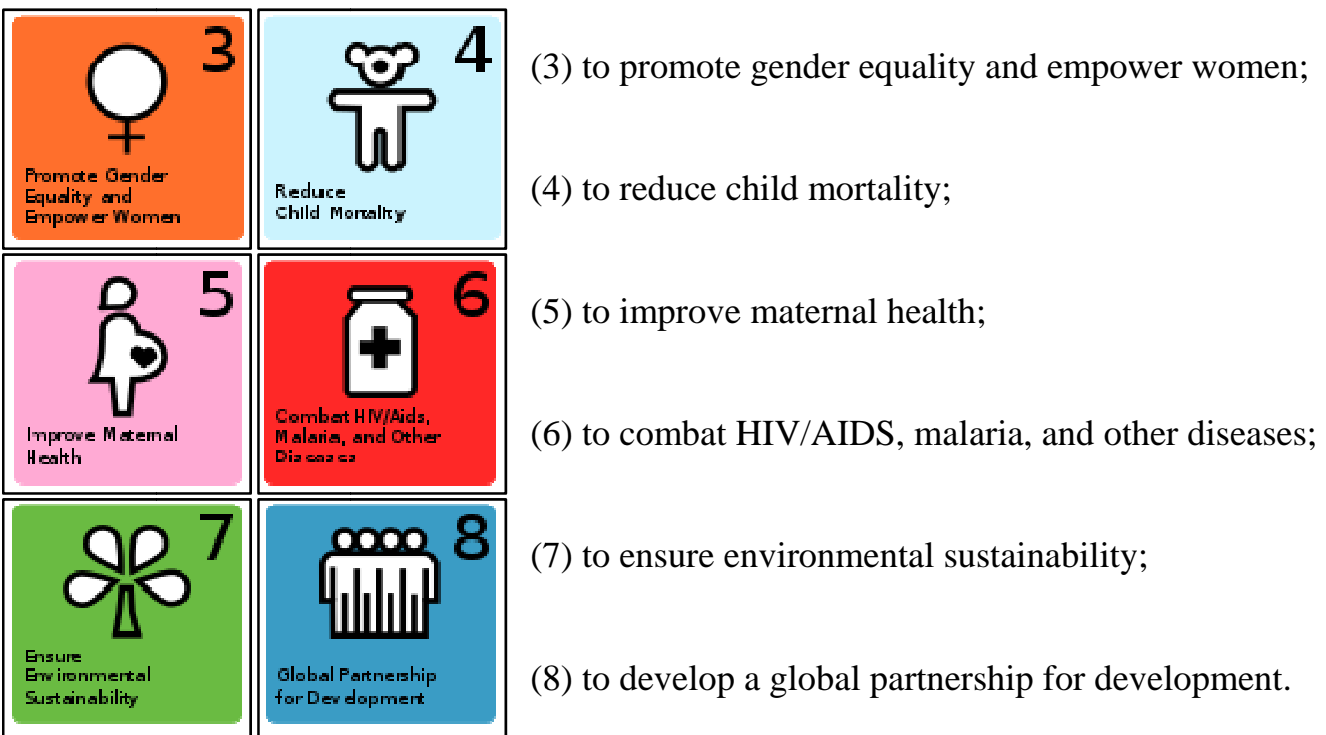

All these above MDGs had indicators interdependent on each other and the most successful movement in the world against poverty alleviation is led by these MDGs. These MDGs elevated more than 1.1 billion people out of extreme poverty (UN Org. Report, Nov. 15, 2016).

Pakistan also adopted these MDGs but was only able to work on 41 indicators, whereas, Pakistan was off track on 33 indicators and was on track on nine and able to achieve some results only on three indicators. The target on which Pakistan was able to make some achievement was poverty alleviation, from 2000-2015 Pakistan was able to reduce poverty to $30 \%$ even after that Pakistan ranked 147th country in the world on poverty line, so overall achievement on MDGs was a complete failure at country level. Universally the MDGs were only able to achieve the overall goals maximum up to $25 \%$ in few countries, whereas, in Pakistan the achievement was less than $1 \%$, mainly in poverty alleviation, as it has passed through the worst time of the history and suffered a lot but survived as a resilience state (Natl. MDGs Orientation of Parliamentary Task Force, 2014, p. 30).

After the expiration of MDGs, in September 2015, the world leaders at UN again made an historical attempt and 191 countries adopted the so called 2030 Agenda for Sustainable Development, depending on 17 Goals and 169 targets (UN. Org. Report, August 23, 2015). The difference was obvious as the MDGs were only set to achieve half of the goals whereas SDGs are designed to completely achieve all the objectives of National Power Elements. The MDGs targeted to receive donation from rich countries for aiding poor, whereas SDGs are set for all countries whether developed or underdeveloped (UN Working Group Report, July 19, 2014). The SDGs are more comprehensive, addressing problems at all levels such as SDGs treat hunger through malnutrition and address countries keeping in view their key problems. In SDGs the peace has also given importance to achieve goals. The SDGs also target monitoring and evaluation by 2020 where in MDGs it was not mentioned. The MDGs were focused on quantity, whereas, SDGs are focused on quality. The SDGs, are therefore universal and have more holistic approach to help the world towards sustainable development by addressing all the key areas and have much wider scope than the earlier planned MDGs (UNDP SDGs Report, Sept. 25, 2015).

The SDGs are more demanding than the MDGs, interconnected with each other, covering social and global issues and all UN focus areas. To apply the SDGs vision, an ambitious plan for financing and implementation is needed. The agenda will require implementation and financial funding at all levels from all 
stakeholders. It is estimated that the cost of eradicate extreme poverty would require about $\$ 66$ billion dollars/year, and the UN estimates that developing countries will face a gap of about three trillion/year to achieve the SDGs. It can only be achieved if the country leadership will have faith in these goals (UN SDGs Report, Oct. 18, 2016).

\section{Sustainable Development Goals (SDGs)}

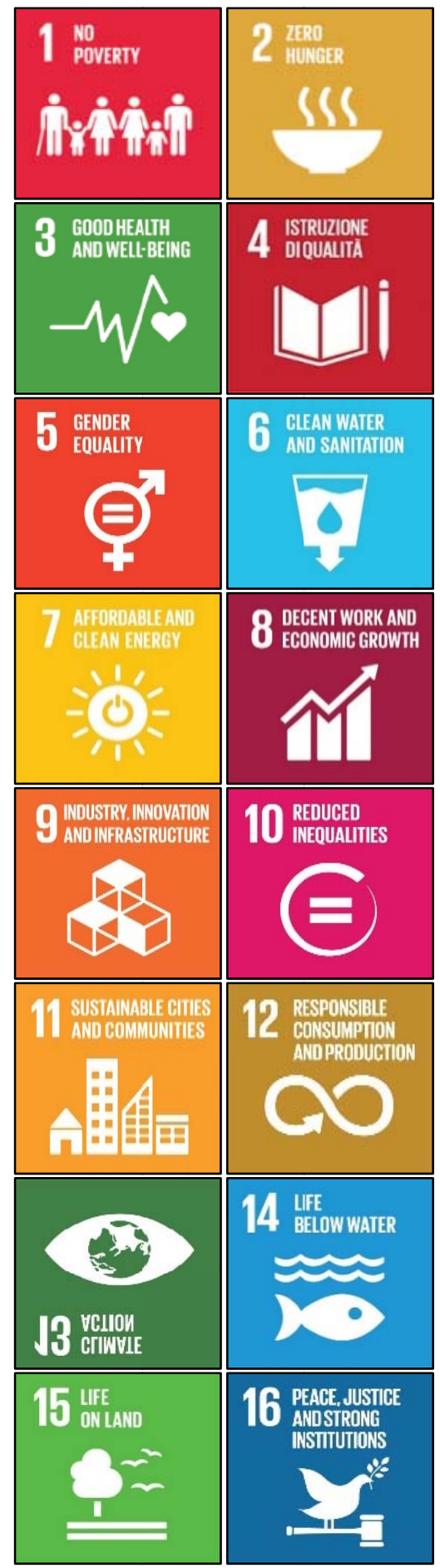

(1) End poverty in all its forms everywhere;

(2) End hunger, achieve food security and adequate nutrition for all, and promote sustainable agriculture;

(3) Ensure healthy life for all at all ages;

(4) Ensure equitable and inclusive quality education and life-long learning opportunities for all;

(5) Attain gender equality, empower women \& girls everywhere;

(6) Secure water and sanitation for all for a sustainable world;

(7) Ensure access to affordable, sustainable, and reliable modern energy services for all;

(8) Promote strong, inclusive, and sustainable economic growth and decent work for all;

(9) Promote sustainable industrialization;

(10) Reduce inequality within and among countries;

(11) Build inclusive, safe, and sustainable cities and human settlements;

(12) Promote sustainable consumption and production patterns;

(13) Promote actions at all levels to address climate change;

(14) Attain conservation and sustainable use of marine resources, oceans and seas;

(15) Protect and restore terrestrial ecosystems and halt all biodiversity loss;

(16) Achieve peaceful and inclusive societies, rule of law, effective and capable institutions; 
PARTNERSHIPS

FOR THE GOALS

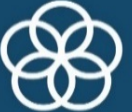

(17) Strengthen and enhance the means of implementation and global partnership for sustainable development.

These above 17 SDGs cover all the UN working areas but for implementation of these SDGs funding required will be about $\$ 7$ trillion/year from different countries which will come into implementation in Jan. 2016 (UN Report. Oct. 11, 2016). The Planning Commission of Pakistan has adopted above United Nation 17 Sustainable Development Goals (SDGs) for the development of humanity and poverty alleviation. Pakistan was not being able to achieve MDGs as we started late, therefore, we have to take SDGs very seriously from the beginning, to achieve their goals, in which poverty alleviation is on top priority (UNDP MDGs Report, Sept. 25, 2015). The action and policies at National level will pay a key role in achieving SDGs by translating SDGs into workable actions (Local Govt. Submit on SDGs, Pakistan, March, 2017).

The SDGs will depend considerably on the inputs of scientists and scientific communities in order to be operative (Yukiya A. IAEA Special Edition, Sept., 2016). The scientific community will be challenged to create systemic approach and understandings with policy relevance at local, country, and international levels (Yukiya, IAEA Bulletin, June, 2017). The role of scientists in handling the SDGs at global, national, and local levels to help integrate sustainability concerns into real actions and engagement between national and international science communities with politicians, civil society, and people to reorganise their knowledge and research to assist in efforts towards crafting the post-2015 development agenda and the implementation of sustainable policies to obtain the anticipated results. Pakistan at this point has no involvement of scientific community and lacks authentic indicators as the basic data required are not available on most of the SDGs.

Many scientific fields can help to achieve these SDGs and one of these, which is the Nuclear Technology can help tremendously in achieving these SDGs (Yukiya, IAEA Bulletin, Sept., 2016). Recently IAEA has played an active role and pointed out that Nuclear Technology can help to achieve 09 out of 17 SDGs and a seminar was held last year and a monograph was published mentioning the nuclear methods which can be utilized achieving SDGs (Nicole \& Miklos, IAEA Bulletin, Sept., 2016). Pakistan’s one national power element is nuclear technology which has given military superiority to it to play important role in the region. Pakistan must create a national sustainable development strategy at country level with appropriate funding to utilize nuclear techniques for the upgradation of mankind. Pakistan as one of the developing country is the largest recipient of the technical and financial help from IAEA. Pakistan has a lot of expertise in application of nuclear technology in medical, agriculture, science and allied fields, this can help in achieving at least 09 goals out of 17 which are discussed along with Pakistani prospective (PAEC Annual Report, 2016).

\section{Nuclear Technology Application to SDGs}

\section{Ending Hunger and Malnutrition}

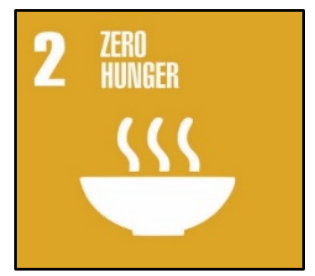

Food is one of the strong national power elements and its production is a vital source of strength for a nation, a shortage of food keeps them dependent on other nations and thus weakens their Sovereignty. The sufficient food depends on development of improved and new crop varieties, these can be developed by radiation mutation with improving productivity, disease resistance, salt tolerance, drought tolerance and with increase 
micronutrients (Goal 2, UNDP Report, Sept. 28, 2015). Insect Pest Management can also be done by using radiation sterilization techniques to safe crops (Nicole \& Miklos, IAEA Bulletin, Sept., 2016). Pakistan is a nation with sufficient food and three institutes are already utilizing nuclear techniques, they have produced about 90 new varieties by radiation mutation of different crops in the last 40 years, covering about 35\% area throughout Pakistan and contributing an increase of $10 \%$ to the crop productivity but its volume has to be further increased. Pakistan is also utilizing irradiation facilities at Lahore to remove harmful bacteria and unwanted insects while extending the shelf life of perish able food. In Pakistan we are also utilizing stable isotope techniques to monitor body composition, food intake and absorption to understand the problems of malnutrition, to decrease the death rate (PAEC Annual Report, 2016). Food security can be achieved by Insect Pest Management by using Male Sterilization Technique, in which insect population is controlled by releasing the radiation sterilized male. This results in increased productivity and helps in achieving the SDG of hunger and malnutrition.

\section{Providing Good Health and Well Being}

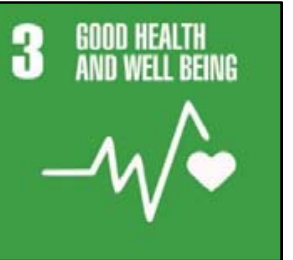

Without health it is impossible to achieve the development targets if people of a country are not healthy and the health conditions are bad, the targets of SDGs cannot be achieved. Therefore, the third SDG can only be achieved if treatment conditions are good and death rate is low (Goal 3, UNDP Report, Sept. 28, 2015). Pakistan has allocated Rs 35-40 billion to upgrade heath programs in 2017-2018. One of the most important utilization of nuclear techniques is nuclear medicine, radiation oncology, radiation facilities and production of radioisotopes and thus the cancer management. This can only be achieved by a well-established cancer control program and well established nuclear medicine and radiation oncology facilities. Nuclear medicine through PET/CT helps in diagnosis whereas radiation or radiotherapy in treatment of cancer. International Agency for Research in Cancer, estimates that about 150 million people are suffering from and by 2030 it will reach over 21 million and about 13 million people/year will die with cancer (Nicole \& Miklos, IAEA Bulletin, Sept., 2016). At present in Pakistan 22 complete cancer diagnostic and treatment facilities are working, whereas, other 10 having either diagnostic or treatment facilities. These facilities are catering about 1,200,000 patients/year. The author has already written on this and given suggestions to Government of Pakistan to immediately implement Cancer Control Program at National Level and to achieve the tertiary health as one of the indicators of this SDG, Pakistan has to seriously start the awareness and Early Diagnosis Cancer Program and has to double State-of-Art Nuclear Diagnosis facilities such as 60 Gamma Cameras, 20 PET Cameras and 20 MRIs and treatment facilities such as 22 LINACs within three years. Other than cancer diagnosis and treat using nuclear technologies precise diagnosis of cardiovascular disease, tuberculosis and other infections can also be done. Nuclear Techniques can also help to control out breaks of animal diseases.

\section{Clean Water and Sanitation}

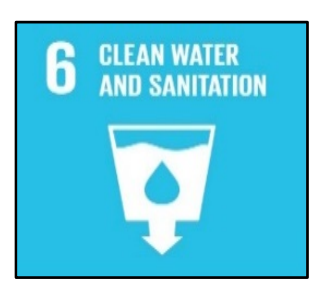

The water is vital for life on the planet earth. Pakistan has already been confirmed as water-stressed country and efficient use of water will be the first requirement for sustainable agriculture production beside this water conservation, ground water management, salinity, and flood control are very important (Goal 6, UN Report, Sept. 28, 2015). Access to safe water should be the top most priority of Government of Pakistan and the 6th SDG ensuring the availability of Clean Water is the most important and difficult goal which Pakistan has to achieve. To help in achievement of different indicators of this goal, the nuclear-isotopic technique 
can be used to collect data and calculate, age of water, quality of water and also in integrated management of water to sustain water resources and water ecosystem. Radiation can also be used to remove bacterial contamination, to treat industrial waste water for making water reusable (Nicole \& Miklos, IAEA Bulletin, Sept., 2016).

\section{Providing Affordable and Clean Energy}

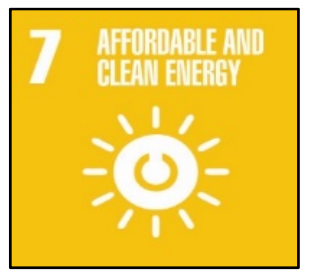

The 7th SDG is providing affordable and clean energy which is a very important target. At the same time the power generation is the basic leading cause of air pollution and greenhouse gases emission in particularly carbon dioxide, one of the largest sources of global warming. Thus the energy production choices will have huge consequences on our health, our economy and risk of irreversible climate change for decades to come (Goal 7 UNDP Report Sept. 28, 2015). As it can be seen the basic contributor to the world electricity is coal and one ton of coal produces 2.8 tons of carbon dioxide. So we have to get rid of coal as energy source. It can only be mitigated through a drastic reduction of carbon dioxide. If we control release of carbon dioxide now and won't add any further $\mathrm{CO}_{2}$ to the atmosphere then we will be able to bring it to zero level after 60 years.

There is better and cleaner way to meet our energy needs which is to produce energy through nuclear power and renewable sources like solar, wind, hydro. Nuclear energy as one of the major low-carbon energy sources, is currently producing about $16 \%$ of total global energy, and many countries believe that it can help them to address the twin challenges of ensuring reliable energy supplies while curbing $13 \%-15 \%$ greenhouse gasses emissions. Besides this nuclear energy is an interrupted source of energy and thus contributes to energy security of the country.

Nuclear energy as green energy can contribute a lot to combat climate change. This can be done by building more nuclear power plants. The first power plant was built in 1950. At present 30 countries are operating 444 nuclear power plants for electricity generation and about 67 new nuclear power plants are under construction in 16 countries, to overcome the energy crisis and to curb the release of carbon dioxide (Nicole \& Miklos, IAEA Bulletin, Sept., 2016).

Almost the same scenario exists in Pakistan. The energy mix is mainly dependent on fossil fuel. Pakistan has already increased its nuclear share from 3\% to 5\% in 2017 and is going to increase its contribution of nuclear energy from $5 \%$ to $14 \%$ of the total energy mix in 2050, as documented by Planning Commission in the 2005 Nuclear Security Plan of lifting the nuclear energy to obtain clean or green and cheap energy. Nuclear power is one of the best options and Pakistan has to increase its Nuclear Energy Share up to 16\% in the energy mix scenario. Pakistan's Nuclear Generation Plan is already given by the Government of 8,800 MW before 2030 and 40,000 MW before 2050 (PD\&R, Pakistan Annual Report, 2017-2018). The Civil Nuclear Program should now be fully supported in order to achieve these targets by putting new nuclear power projects, capacity building and developing nuclear knowledge, the only way out to achieve this SDGs is to invest in nuclear power projects.

\section{Sustainable Industry Innovation and Infrastructure}

(1) INDUSTRY INNOVAIION (1) AND IIFRASTRUGIURE

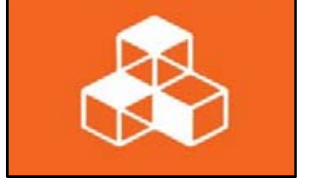

Infrastructure and cutting edge technologies are required to increase industrial growth (Goal 9, UNDP, Sept. 28, 2015). Nuclear science can contribute and support in achieving indicators of this SDG. Non-destructive X-ray techniques can be used for safety and quality testing of the products such as buildings and bridges. Irradiation techniques can also be used to improve durability of products, i.e. wires, cables, pipes, car tires etc. 
Radiation technology can be used to remove bacteria from single use medical products and insect removal of pests from food and thus to increase shelf life of the food commodities, like onions, potatoes, spices, and mangoes (Nicole \& Miklos, IAEA Bulletin, Sept., 2016). In this regard one medical and one food irradiator is already working at Lahore. To get benefit of this technique more irradiators are needed to be installed at Gwadar, Karachi, and Gilgit. This in turn will increase our exports and foreign exchange earnings.

\section{Mitigation of Climate Change}

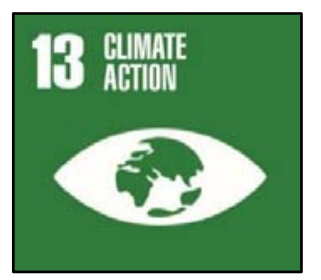

Climate has a very important role in national power as temperature controls the food production and thus the economy of a country. The goal of this 13th SDG is regulated by the release of carbon dioxide. Climate change mitigation is one of the leading reasons for progressively considering nuclear power increase share in national energy mix. Nuclear power should also be considered in climate change revision actions. The greenhouse gases have an average life time in atmosphere of 50-200 years, if the emission of greenhouse gases stopped now, even then it is foreseen that a definite increase in carbon dioxide emission will continue till 2030 (Goal 13, UNDP Report, Sept. 28, 2015). Nuclear power can play substantial role in reducing greenhouse gas emission and thus in easing of climate change. Nuclear power is called as green energy and is one of cleanest technologies beside wind and hydro.

There is another worldwide picture that a build rate of 58-60 new reactors per year could entirely replace current fossil fuel electricity generation by 2050. Accounting for increased global electricity demand driven by population growth and development in poorer countries, add another 55 reactors per year, this makes a total requirement of about 115 reactors per year up to 2050 to entirely decarbonize the global climate scenario (Nicole \& Miklos, IAEA Bulletin, Sept., 2016). Pakistan also has to increase the role of nuclear power contribution in its energy mix to mitigate climate change it was 3.6\% up to 2016 and now after installation of C-3 and C-4, it has increased up to $5.2 \%$. Pakistan will be looking to increase nuclear power production up to $14 \%$ in the coming 30 years (PAEC Annual Report, 2017).

Energy production is one of the biggest contributors of the carbon dioxide. The target of this SDG is mitigation of climate change by adopting different cleanest method of energy production. Nuclear power can play significant role in reducing greenhouse gas emission and thus in mitigation of climate change. It is one of cleanest technologies besides wind and hydro. About 11 billion tons of carbon dioxide is released every year. Pakistan has to increase the role of nuclear power contribution in its energy mix to mitigate climate change.

American Nuclear Society, French Nuclear Society, and European Nuclear Society have formed a global alliance of about 39 Nuclear Societies and associations in support of a communication initiative called "Nuclear for Climate” by declaring that nuclear energy is a key part of the solution in the fight against climate change. The initiative is considered to improve awareness, particularly among world leaders of the important role of nuclear energy in lowering carbon dioxide emission thus affecting global climate change. It is essential that legislators recognize that nuclear energy delivers large amounts of continuous, economically cheaper electricity with no carbon dioxide emissions and is among the lowest lifecycle carbon emissions.

\section{Sustainability of Life Below Water}




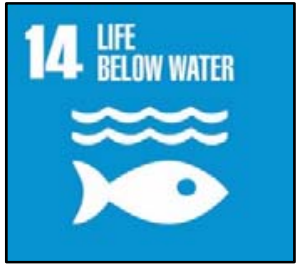

The marine life is an important source to provide food and nutrition to the human beings and support coastal population (Frangoul, CNBC, June 6, 2017). It is essential to sustain this source and the indicators of this SDG (Goal 14, UNDP, Sept. 28, 2015). The marine life can better understand and be controlled by using diagnostic power of isotopic techniques. The information such as ocean acidification can be obtained utilizing nuclear techniques. This can help scientists to understand and monitor and control pollutants and ocean health. The isotopic techniques information can be used to control pollution in marine system, the stable isotopes can be measured for industrial pollution (Nicole \& Miklos, IAEA Bulletin, Sept., 2016).

\section{Sustainability of Life on Land}

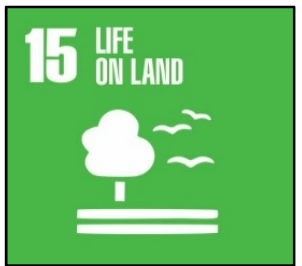

In world 1.9 million acres are under erosion. Soil erosion and land degradation can harm people living nearby and the economy of the country (Goal 15, UNDP Report, Sept., 2015). Many countries have controlled this by utilization of nuclear techniques. Isotopic techniques can be used to find out hot spots and soil erosion rates can be estimated which can help to restore soils, ecosystems, and biodiversity. IAEA is supporting many countries in this area to reshape their agriculture practices, protection of resources, and biodiversity (Nicole \& Miklos, IAEA Bulletin, Sept., 2016). In Pakistan isotopic techniques are helping in controlling saline land and reversing the process of making the land suitable for cropping which is at present more than $30 \%$ of total cropping area (PAEC Annual Report, 2016).

\section{Strengthening Partnerships for Achieving Sustainable Development Goals}

PARTIERRYIIPS

FOR THE GOALS

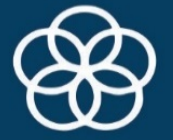

To achieve these SDGs partnerships should be developed with many United Nation organizations, such as World Health Organization (WHO), Food \& Agriculture Organization (FAO), International Atomic Energy Agency (IAEA), and other international organizations (Dazhu, IAEA Bulletin, June, 2017; Goal 17, UNDP, Sept. 28, 2015). For the utilization of nuclear techniques, the Pakistan Government has to increase partnership with IAEA and Pakistan Atomic Energy Commission (PAEC), its focal point in Pakistan. PAEC is already playing its important role in the peaceful utilization of Nuclear Techniques. Four civil nuclear power plants are already working providing uninterrupted 5\% nuclear energy to the energy mix and working on a program to increase it up to 14\%-16\%, 18 cancer hospitals treating more than 900,000 patients/year and looking forward to increasing these hospitals to 20 by the end of 2018 (PAEC Annual Report, 2016).

There are three agricultures and one biotechnology institute contributing to agriculture sector by introducing different mutation varieties. Engineering \& S\&T centers are providing support to industrial infrastructure and to civil nuclear power program as well as collaborating to international institutes such as IAEA and CERN (PAEC Annual Report, 2016).

\section{Conclusion}

Pakistan's challenge is to mobilize SDGs to achieve its National Power Elements, for that it has to include and increase nuclear techniques role in achieving different indicators of SDGs and has to include utilization of nuclear technology in its country program framework. Pakistan is lucky to have knownhow and trained manpower in the field nuclear technology and is one of the highest recipients of financial and technical help of IAEA in Asia. Now, there is a need of political will to channelize this knowhow and manpower to implement the 
vision and agenda by moving coherently with UN and IAEA to achieve these sustainable development goals at national level by 2030 .

\section{References}

Dazhu, Y. (2017). IAEA TC program-Building partnerships for progress. IAEA Bulletin, June, p. 21.

Frangoul, A. (2017). UN secretary general gutierrez says world's oceans are facing unprecedented threat. CNBC, June 6.

High level panel—The post 2015 development agenda. ( 2016). Post-2015hlp.org. October 11.

Local government submit on SDGs. (2017). Pakistan. March.

National MDGs orientation of parliamentary task force; Social Development in Pakistan; Gaps and Challenges, 2014 , p. 30.

Nicole, J., \& Miklos, G. (2016). The sustainable development goals and IAEA. IAEA Bulletin, September, pp. 4-5.

PAEC Annual Report. (2016-2017).

Planning Development and Reforms Division, Planning Commission of Pakistan Annual Report. (2017-2018).

Transforming our world: The 2030 agenda for sustainable development. United Nations—Sustainable development knowledge platform. August 23, 2015.

Sustainable Development.UN. Org. (2014). Press release-UN General Assembly’s Open Working Group proposes sustainable development goals (PDF). July 19.

Sustainable Development UN. Org. (2016). Future we want-Outcome document. Sustainable Development Knowledge Platform. October 11.

United Nations Development Program. (2015). Millennium development goals. September 25.

United Nations Development Program. (2015). Paris Climate Change Conference: COP21. September 28.

United Nations Development Program. (2015). World leaders adopt sustainable development goals. September 25.

UNDP. (2015). Goal 2: Zero hunger. Sept. 28.

UNDP. (2015). Goal 3: Good health and well-being. Sept. 28.

UNDP. (2015). Goal 6: Clean water and sanitation. September 28.

UNDP. (2015). Goal 7: Affordable and clean energy. September 28.

UNDP. (2015). Goal 9: Industry, innovation, infrastructure. September 28.

UNDP. (2015). Goal 13: Climate action. September 28.

UNDP. (2015). Goal 14: Life under water. September 28.

UNDP. (2015). Goal 15: Life on land. September 28.

UNDP. (2015). Goal 17: Partnerships for the goals. September 28.

UN. Org. (2016). Secretary-General's remarks to the press at COP22. November 15.

UNSCD Org. (2016). The future we want-Outcome document of the United Nations Conference on Sustainable Development (PDF). October 18.

UN. Org. (2016). United Nations official document. October 11.

Yukiya, A. (2016). Building sustainable future: Atom for peace and development. IAEA Bulletin, September, p. 1.

Yukiya, A. (2016). 60 years of IAEA. IAEA Special Edition, September, p. 1.

Yukiya, A. (2017). Sixty Years and Beyond-Contributing to development. IAEA Bulletin, June, p. 1. 